\title{
Effect of Process Parameters on the Angular Distribution of Sputtered Cu Flux in Long-Throw Sputtering System
}

\author{
Hee-Young Shin ${ }^{1,2}$, Tae-Ho Kim¹, Jun-Woo Park ${ }^{3}$, and Hyun-Chul Sohn ${ }^{1, *}$ \\ ${ }^{1}$ Department of Materials Science and Engineering, Yonsei University, Seoul 03722, Republic of Korea \\ ${ }^{2}$ SK Hynix, Ichon 17336, Republic of Korea \\ ${ }^{3}$ AP system, Dongtan 18487, Republic of Korea
}

\begin{abstract}
In this work, the angular distribution of the sputtered $\mathrm{Cu}$ flux in a long throw sputtering (LTS) system is extracted from the comparison of experimentally-measured profiles of deposited films with simulated profiles of films in overhang contact structure. And effects of the sputtering process parameters such as Ar pressure during sputtering, $\mathrm{RF}$ power on substrates, and DC power on $\mathrm{Cu}$ target are investigated for a DC magnetron sputtering system with LTS. The bottom step coverage in contact is enhanced with decreasing operating pressure and is increased with increasing substrate RF power up to $200 \mathrm{~W}$. However, the bottom step-coverage was reduced with substrate RF power above $400 \mathrm{~W}$, possibly due to the re-sputtering effect of the deposited $\mathrm{Cu}$ films. $\mathrm{DC}$ power on $\mathrm{Cu}$ target does not affect the angular distribution of $\mathrm{Cu}$ atoms while the overall deposition rate is increased. Based on the estimated angular distribution of sputtered $\mathrm{Cu}$ flux, the profile of $\mathrm{Cu}$ film is deposition on a deep via of aspect ratio 10 and compared to the simulation of the film profile that shows a good agreement.
\end{abstract}

(Received February 27, 2019; Accepted May 21, 2019)

Keywords: DC magnetron sputtering, flux distribution, step coverage, long throw sputter, simulation

\section{INTRODUCTION}

In recent semiconductor devices, the through-silicon-via (TSV) technology is introduced to overcome the restriction by wire connection and the signal delay as the number of cells increases [1,2]. During the TSV processes, chips are connected by via hole of high aspect ratio. Then, barrier layer and seed layer are formed using the physical vapor deposition (PVD) method in via holes and then $\mathrm{Cu}$ films are deposited to fill via holes [3].

The conventional sputtering has a wider angular distribution of arrival atoms that induces a pinch-off of the barrier and the seed layers at the top, producing a nonconformal film profile with the poor coverage at the bottom and the side of vias $[4,5]$. To obtain a conformal film in the high aspect ratio via structure, the angular flux of the sputtered $\mathrm{Cu}$ toward to the bottom of the deep via needs to

- 신희영·박준우: 연구원, 김태호: 박사과정, 손현철: 교수 *Corresponding Author: Hyun-Chul Sohn

[Tel: +82-2-2123-5850, E-mail: hyunchul.sohn@yonsei.ac.kr]

Copyright (c) The Korean Institute of Metals and Materials be enhanced to produce a relatively thick film at the contact bottom [6]. As the distance between target and substrate increases, the range of the angle of the atomic flux that is reaching the substrate is decreased naturally such that the deposition can be added to the bottom of the structure $[7,8]$. The angular distribution of atoms sputtered from the target is significant effect on the step coverage and the deposition profile [9] and the understanding of effects of sputtering process parameters on the angular distribution of sputtered atoms is important to control the deposition profile of films on deep vias [10-12]. LTS method is applied to improve the step coverage at via bottoms by enhancing the atomic flux toward a contact bottom. In the LTS method, atoms with large deviation angles are separated from the wafer and only a narrow angle of flux reaches the substrate.

In this study, the angular distribution of sputtered $\mathrm{Cu}$ atoms for LTS are investigated by the comparison of the deposition profile measured in overhang structures with the simulated deposition profile from various angular fluxes with the shape of cosine law. And effects of the sputtering parameters such as the substrate RF power, the operation pressure, and the 
target DC power on the angular distribution of $\mathrm{Cu}$ are investigated. Then, the deposition profile of sputtered $\mathrm{Cu}$ films on the deep via of aspect ration 10 is simulated based on the optimized sputtering conditions and compared with the measured $\mathrm{Cu}$ film profile to check the validity of the optimized atomic flux.

\section{EXPERIMENTAL PROCEDURES}

Bulb-shaped contact structures of low aspect ration of $<2$ with overhang are fabricated to extract angular distributions of sputtered $\mathrm{Cu}$ and to investigate the effect of the sputtering process conditions on deposition profile of $\mathrm{Cu}$ films. To make contact structure with overhang, $\mathrm{SiO}_{2}$ of $2 \mu \mathrm{m}$ is deposited using low pressure chemical vapor deposition (LPCVD) using tetraethyl orthosilicate (TEOS) and then, the silicon nitride film of $0.4 \mu \mathrm{m}$ is deposited using LP-CVD. After patterning the $2 \mu \mathrm{m}$ hole using photolithography, the silicon nitride is dry etched with RIE to form holes, then $\mathrm{SiO}_{2}$ is etched by the wet etchant of $0.5 \% \mathrm{HF}$ solution to form overhang structure. $\mathrm{Cu}$ films are deposited on the overhang structure by the AP systems' LTS sputter system with the sample-target distance of $380 \mathrm{~mm}$. Then the profile and step coverage are measured using cross-sectional transmission electron microscopy (TEM) of JEOL JEM-2100. Simulation of the deposition profiles is conducted using the Athena program, which can be applied to PVD deposition. For simulation, the hemispherical model in the Athena program by Silvaco is used to represent the successive deposition distributions for different incident angles. The angular distribution of sputtered $\mathrm{Cu}$ atoms is extracted from the simulated deposition profile that matches the measured profile. Then, the optimized process condition is applied to the deep contact with aspect ratio of 10 and the measured profile of $\mathrm{Cu}$ film is compared with the simulated deposition profile to validate the extracted angular distribution of atomic flux.

\section{RESULTS AND DISCUSSION}

The main factor that determines the bottom step coverage and the deposition profile is the angular distribution of the sputtered flux. In general, the angular distribution of sputtered atoms can be expressed as the following formula [10-12]

$$
\frac{d Y}{d \Omega}=Y_{\text {total }}\left(\frac{\cos \theta}{\left(\rho \sin ^{2} \theta+\cos ^{2} \theta\right) \pi}\right)
$$

where $Y_{\text {total }}$ is the total integrated yield, $\theta$ is the cone angle, $\rho$ is the fitting (an empirical parameter), and $d \Omega$ is the differential solid angle in the direction of emission. $\rho<1$ indicates the under-cosine distribution, $\rho>1$ implies the over-cosine distribution. Therefore, the large $\rho$ value with the over-cosine distribution increases the directionality of the sputtered atoms towards the substrate, thus improving the bottom coverage [13]. To empirically determine the value of $\rho$, we use both simulation and the empirical measurement of film profiles on overhang structures. With the assumption that the angular distribution has an elliptical shape (cosine law), the amount of flux for each angle can be calculated as the length of the vector.

$$
x_{i}=\frac{2 a^{2} b \cos \theta_{i}}{a^{2} \sin ^{2} \theta_{i}+b^{2} \cos ^{2} \theta_{i}}
$$

where $x_{i}$ is the scalar length of the vector, $\theta$ is the cone angle, $a$ is the length of the short axis, $b$ is the length of the long axis, and $\rho$ is $b / a$. As shown Fig. 1 , each of the fluxes passing through the hole is deposited continuously on the bottom surface. The amount of each flux depends on the value of $\rho$ and can be calculated using Equation (2). Integration of the magnitude of flux can produce the deposition profile of the bottom. Then, the value of $\rho$ is determined from the best match between the simulated profile of the films and the empirical film profile.

Figure 2 shows empirical profiles of films and simulations at two different working pressure for $\mathrm{Cu}$ sputtering where the DC power, the substrate RF power, and deposition time were set at $40 \mathrm{~kW}, 0 \mathrm{~W}$, and $60 \mathrm{~s}$ respectively. The decrease in the working pressure produces the increase in the top-to-bottom step coverage from 0.4 at 10 mTorr in Fig. 2(b) to 0.7 at 0.5 mTorr in Fig. 2(a), where the bottom step coverage is defined as the ratio of the film thickness at the bottom to the film thickness at the top of contact. As the working pressure decreases, the mean free path (MFP) of the $\mathrm{Cu}$ atoms is increased, resulting less collisions of the sputtered $\mathrm{Cu}$ [14]. The MFP of $\mathrm{Cu}$ atoms is estimated to be $380 \mathrm{~mm}$ at $298 \mathrm{~K}$ 


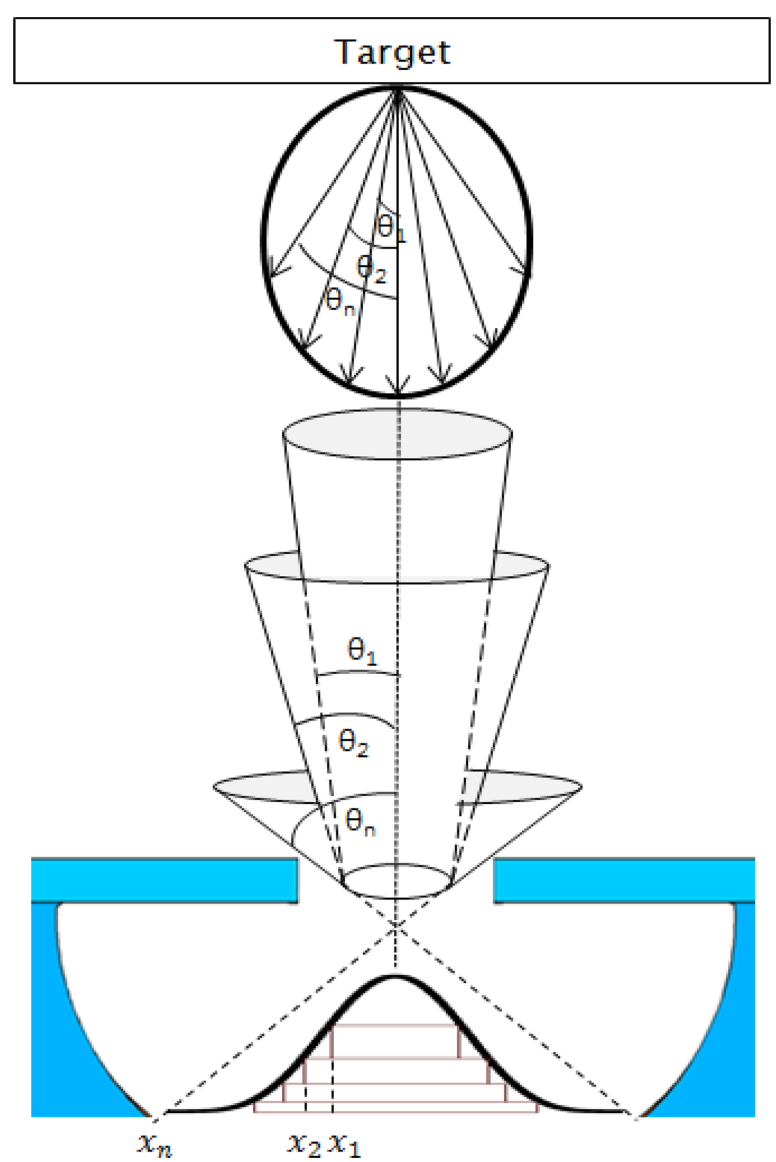

Fig. 1. Schematic diagram of the angular distribution of sputtered atomic flux and the thickness profile of a film deposited at the bottom of jar-shaped contact pattern. (a)

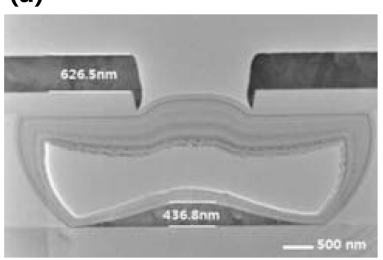

(b)

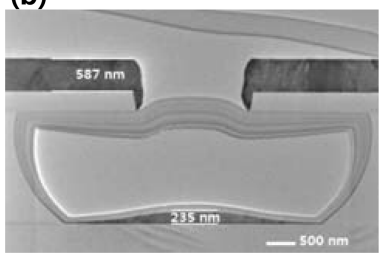

(c)

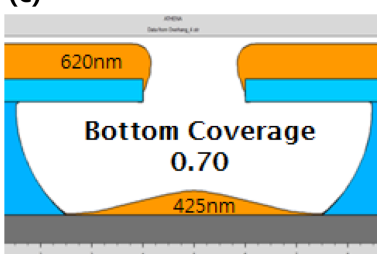

(d)

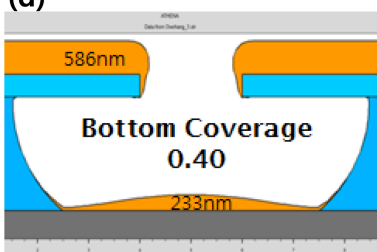

Fig. 2. Cross-sectional TEM images of deposited $\mathrm{Cu}$ films and simulated $\mathrm{Cu}$ profiles at the bottoms of jar-shape-patterns with varying $\mathrm{Ar}$ pressure. For the deposition of $\mathrm{Cu}$ film, $\mathrm{DC}$ power, substrate RF power, and deposition time were set to $40 \mathrm{~kW}, 0 \mathrm{~W}$, and $60 \mathrm{~s}$, respectively. Ar pressure during $\mathrm{Cu}$ sputtering was set to be (a) 0.5 mTorr and (b) 10 mTorr. Simulated Cu profiles (c) with $r$ value of 2.43 for Ar pressure of $0.5 \mathrm{mTorr}$, and (d) with $\mathrm{r}$ value of 1.01 for Ar pressure of $10 \mathrm{mTorr}$. and at 0.9 mTorr $[15,16]$. In this work, the MFP of $\mathrm{Cu}$ is comparable to the target-substrate distance of $380 \mathrm{~mm}$. It is expected that directionality is improved without scattering of $\mathrm{Cu}$ atoms, resulting in better step coverage at the bottom. However, if the working pressure is too low, the maintaining plasma would be reduced, with the reduced deposition rate. Long throw sputtering is technique used to control the angular distribution [17]. In standard sputtering configurations, there are two primary reasons for a wide angular distribution of incident flux: first, the distance of a small target to substrate, and secondly, the scattering of the flux by the neutral working gas as the flux travels from the target to the substrate. A method to achieve narrow angular distribution is to use the long throw sputtering systems in which the target can be sputtered at very low pressures [18].

Figure 2(c)-2(d) show simulated profile of the deposited films carried out at working pressures of $0.5 \mathrm{mTorr}$ and 10 mTorr, respectively. The angle of the flux deposited on the bottom through the hole was set to be $0-53$ degrees in the simulation. As the pressure decreases, the bottom coverage was increased with the increased magnitude of flux toward the substrate. The best fit $\rho$ values are extracted for the working pressure of $0.5,1,5$ and 10 mTorr by considering the deposition rate and distribution using equations (1) and (2). The fit $\rho$ value was estimated to be $2.43,1.93,1.45$, and 1.01 for the pressure of $0.5,1,5$ and 10 mTorr, respectively, as shown in Fig. 5 (a). Even though the pressure of 0.5 mTorr shows the highest $\rho$ value with the increased flux toward the substrate, the working pressure of $1 \mathrm{mTorr}$ was used for the subsequent experiment since the plasma formation appears to be more stable than the working pressure of 0.5 mTorr.

Figure 3 shows a series of experiments and simulations in which the substrate RF power was set to $0 \mathrm{~W}, 200 \mathrm{~W}$, and $600 \mathrm{~W}$ with the DC power of $40 \mathrm{~kW}$, the working pressure of $1 \mathrm{mTorr}$, and the deposition time of $60 \mathrm{~s}$. As shown in Fig. 3(a) and 3(b), the step coverage at the bottom is improved to 0.71 for the RF power of $200 \mathrm{~W}$ from 0.6 for the no substrate $\mathrm{RF}$ power. It is considered that the increase of bottom step coverage is attributed to the increased $\mathrm{Cu}$ flux towards the contact bottom with increasing substrate RF power, resulting in the over-cosine shape of flux distribution $[19,20]$. When the substrate RF power was increased further to $600 \mathrm{~W}$, the bottom coverage was significantly decreased to 0.57 , as 
(a)

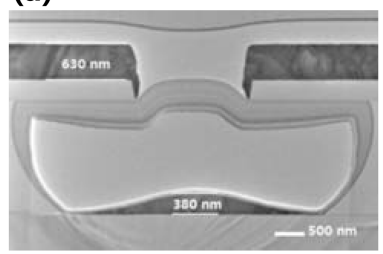

(b)

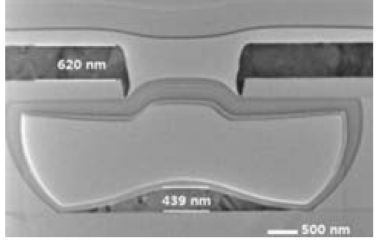

(c)

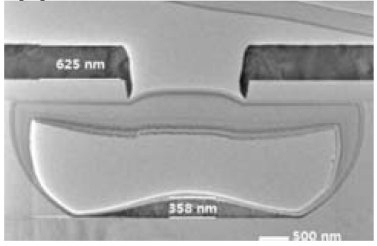

(d)

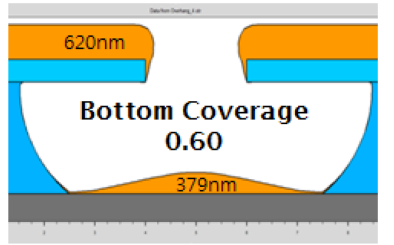

(e)

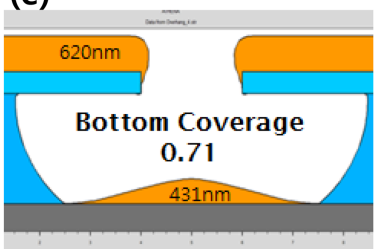

(f)

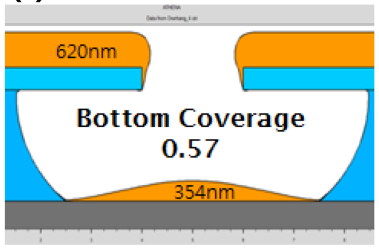

Fig. 3. Cross-sectional TEM images of the deposited $\mathrm{Cu}$ films and simulated $\mathrm{Cu}$ profiles at the bottoms of jar-shape-patterns with varying substrate RF Power. For the deposition of $\mathrm{Cu}$ film, DC power, Ar pressure, and deposition time were set to $40 \mathrm{~kW}, 1 \mathrm{mTorr}$, and $60 \mathrm{~s}$, respectively. The RF power was set to be (a) $0 \mathrm{~W}$, (b) 200 $\mathrm{W}$, and (c) $600 \mathrm{~W}$. Simulated Cu profiles (d) with $\mathrm{r}$ value of 1.93 for the RF power of $0 \mathrm{~W}$, (e) with $r$ value of 2.60 for the RF power of $200 \mathrm{~W}$, (f) with $\mathrm{r}$ value of 1.70 for the RF power of $600 \mathrm{~W}$.

shown in Fig. 3(c). Such a reduction of film thickness is considered to be due to re-sputtering of $\mathrm{Cu}$ [21]. It was reported that the re-sputtered $\mathrm{Cu}$ from the bottom was redeposited on the sidewall and thus the sidewall thickness could be increased [22,23].

For the substrate RF power of $0 \mathrm{~W}, 200 \mathrm{~W}, 400 \mathrm{~W}$ and 600 $\mathrm{W}$, the best $\rho$ values are estimated to be 1.93, 2.60, 2.17, and 1.70, respectively, as shown in Fig. 5(b).

Figure 4 shows cross-sectional TEM images of films and simulation images for the DC sputtering power of $10 \mathrm{~kW}$ and $40 \mathrm{~kW}$. For the film deposition, the substrate RF power, the pressure, and the deposition time was set to $0 \mathrm{~W}, 1 \mathrm{mTorr}, 60$ $\mathrm{s}$, respectively. As the DC sputtering power increases from 10 $\mathrm{kW}$ to $40 \mathrm{~kW}$, the film thickness is increased but no change in the bottom coverage was observed, indicating that $\rho$ is not affected by DC sputtering power, as shown in Fig. 5 (c). It is expected that the increase on the DC puttering power causes the sputtering yield of $\mathrm{Cu}$ atoms to be increased but does not change the angular distribution of sputtered $\mathrm{Cu}$ atoms, resulting

(a)

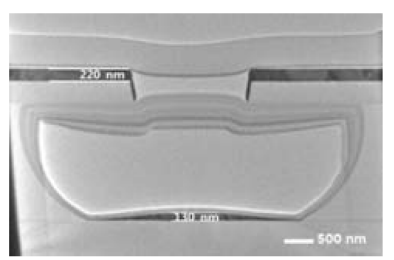

(b)

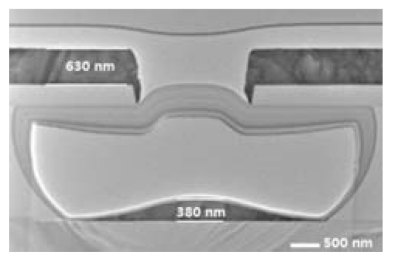

(c)

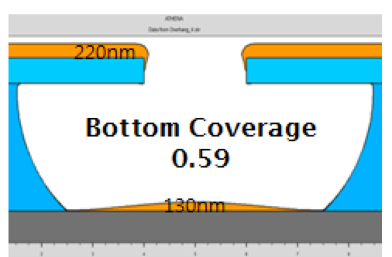

(d)

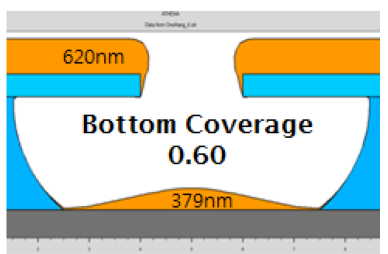

Fig. 4. Cross-sectional TEM images of the deposited $\mathrm{Cu}$ films and the simulated $\mathrm{Cu}$ profiles at bottoms of jar-shape-patterns with varying DC Power. For the deposition of $\mathrm{Cu}$ film, RF power, Ar pressure, and deposition time were set to $0 \mathrm{~kW}, 1 \mathrm{mTorr}$, and $60 \mathrm{~s}$, respectively. The DC power was set to be (a) $10 \mathrm{~kW}$, (b) $40 \mathrm{~kW}$ The simulated profiles of $\mathrm{Cu}$ films (c) with $\mathrm{r}$ value of 1.93 for the $\mathrm{DC}$ power of $10 \mathrm{~kW}$ and (d) with $r$ value of 1.93 for the DC power of 40 $\mathrm{kW}$.

in the thicker films with similar deposition profile [24].

From the experiment, it is shown that the angular distribution of sputtered $\mathrm{Cu}$ atoms is strongly dependent on the base pressure and the substrate RF power, affecting the bottom step coverage after film deposition. The $\rho$ value that determines the angular distribution can be expressed as a quadratic function for substrate RF power that is inversely proportional to pressure. The formula, obtained from the trend line, is expressed as the following.

$$
\rho_{\text {total }}=a \times \mathrm{RF}^{2}+b \times \mathrm{RF}+c
$$

where $a$ is $(-1)\left(1.8 \times 10^{-6} /(P+0.0129)+5.3 \times 10^{-6}\right), b$ is $(0.032 /$ $(P+0.59))+0.00167, c$ is $(1.717 /(P+0.57))+0.88$, RF is the substrate RF power (W), and $\mathrm{P}$ is the pressure (mTorr).

Based on the above equation, the optimum process condition with the highest bottom step coverage is expected to be the pressure of $0.5 \mathrm{mTorr}$, the substrate RF power of $200 \mathrm{~W}$, and for DC power of $40 \mathrm{~kW}$ with $\rho$ value of $\sim 3.1$. To validate the optimization for the improved bottom step coverage, $\mathrm{Cu}$ films are deposited on the deep contact with diameter of $5 \mu \mathrm{m}$, aspect ratio of 10 and the profile of the deposited $\mathrm{Cu}$ films is compared with the simulation of the $\mathrm{Cu}$ film with the of 3.1 .

Figure 6(a)-6(d) show the measured profile of $\mathrm{Cu}$ films by 

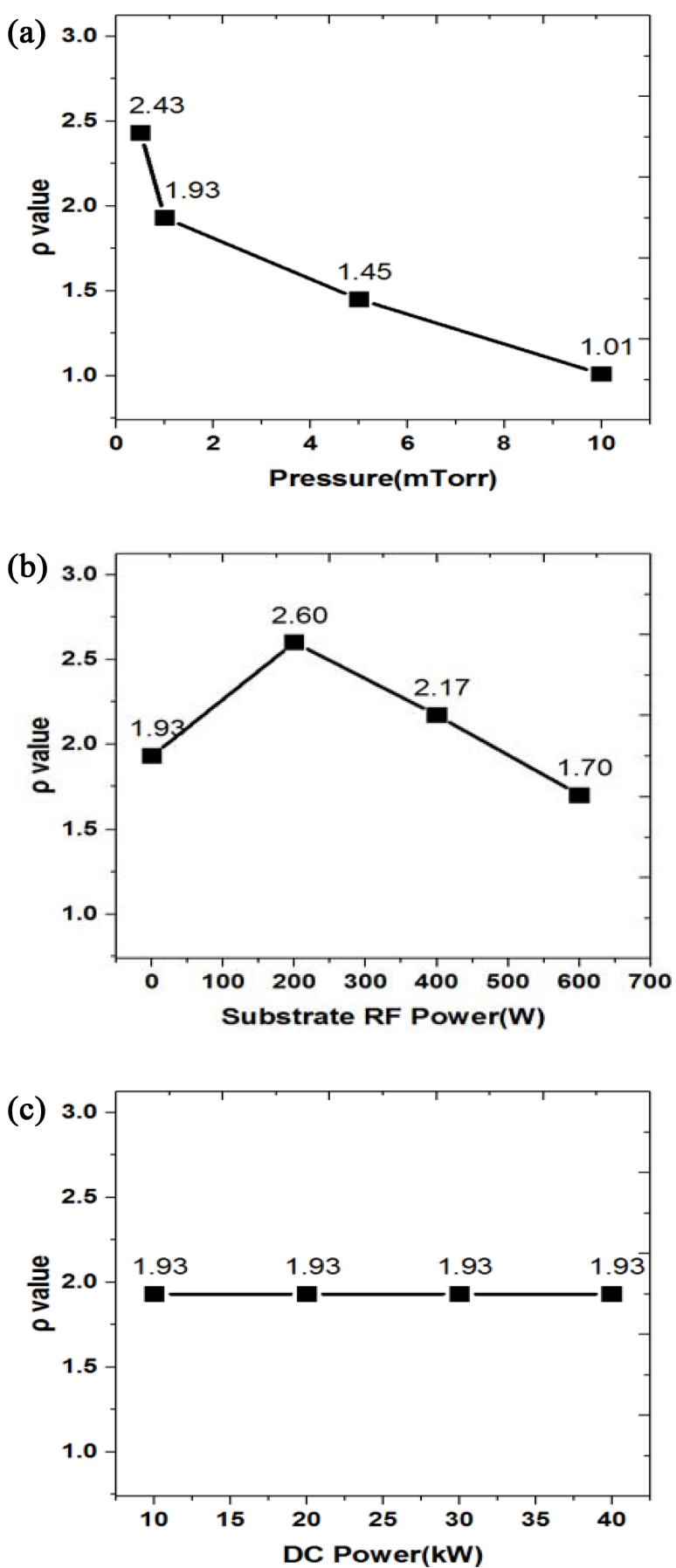

Fig. 5. $\rho$ values that were estimated for various sputtering parameters (a) of operation pressure, (b) of substrate RF power, and (c) of DC power for target.

TEM and simulation images for a DC power of $40 \mathrm{~kW}$, a pressure of 0.5 mTorr, and a substrate RF power of $200 \mathrm{~W}$. Experimental measurement of $\mathrm{Cu}$ profile shows the film profile at the side and the bottom of the contact, where the film thickness is reduced as the distance from the contact (a)

(b)
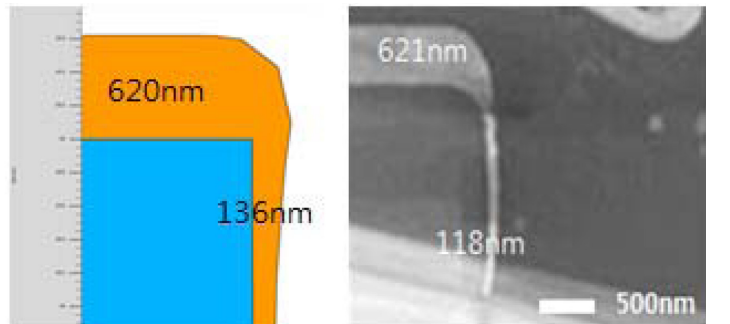

(c)

(d)
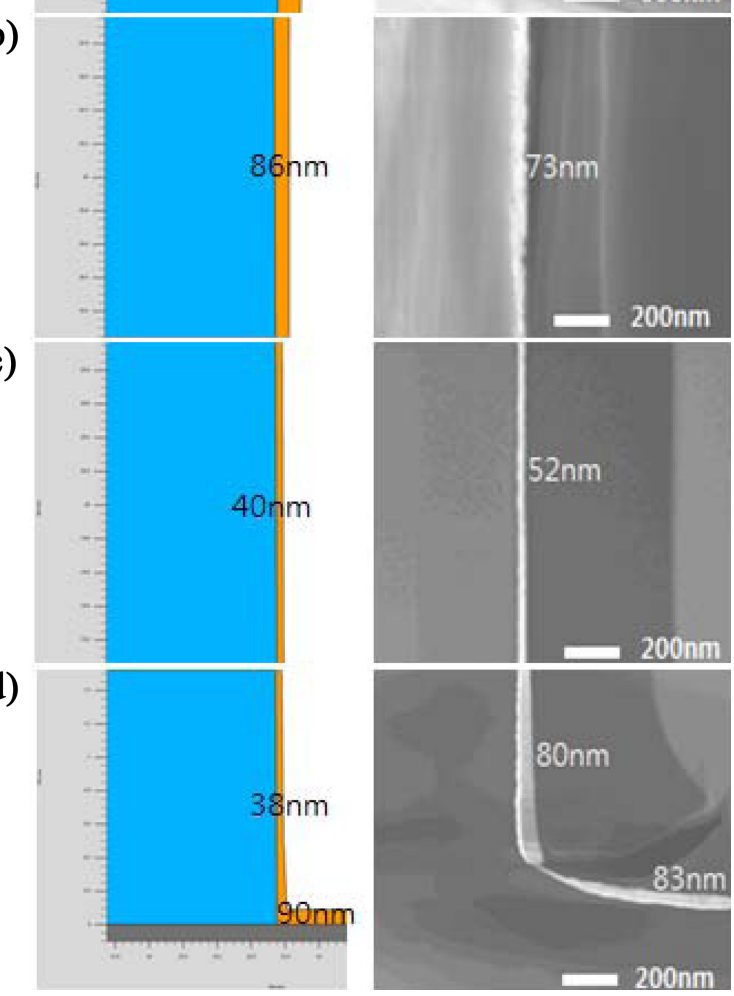

Fig. 6. The simulated thickness profile of $\mathrm{Cu}$ film and the crosssectional SEM images of $\mathrm{Cu}$ films deposited on a deep contact of aspect ratio 10 (a diameter of $5 \mu \mathrm{m}$ ) (a) at the top of contact, (b) 10 $\mu \mathrm{m}$ from the top, (c) $20 \mu \mathrm{m}$ from the bottom, and (d) at the bottom of a deep contact hole, respectively. For $\mathrm{Cu}$ sputtering, DC power, pressure, substrate RF power, and deposition time were set to 40 $\mathrm{kW}, 0.5 \mathrm{mTorr}, 200 \mathrm{~W}$, and $60 \mathrm{~s}$, respectively.

opening is increased, which is similar to the simulation of deposited film in deep contact. The extraction of $\rho$ values from comparison of experimental film profile with simulation profile using the overhang structure is useful tool to extract angular distribution of the sputtered atom at various sputtering conditions.

\section{CONCLUSIONS}

In this study, the angular distribution of sputtered $\mathrm{Cu}$ atoms in long-through sputtering system is investigated by the 
comparison of the deposition profile measured in overhang structures with the simulated deposition profile from the cosine law. Also effect of the sputtering process parameters such as the operating pressure, the substrate RF power, and the DC target power are investigated. Reducing operating pressure enhances the over-cosine distribution with increased bottom step coverage in the contact. Increasing the substrate RF power also enhances the over-cosine distribution but reduces the bottom step coverage with too high $\mathrm{RF}$ power. DC target power, however, does not affect the angular distribution of sputtered $\mathrm{Cu}$ atoms even though the sputtering yield is increased with increasing DC power. Also it is demonstrated that the optimum sputtering condition for high bottom step coverage for deep contact is deduced from effects of process parameters and is validated with the deposition profile of $\mathrm{Cu}$ films in the deep contact of aspect ratio of 10 .

\section{ACKNOWLEDGEMENTS}

This work was supported by the Ministry of Trade, Industry \& Energy (MoTIE, Korea) under Industrial Strategic Technology Development Program (Grant no. 10067481) the R\&D Program of the industry-university cooperation project of SK hynix Inc., and the Brain Korea 21 plus projects (BK21 plus).

\section{REFERENCES}

1. S. Spiesshoefer, Z. Rahman, G. Vangara, S. Polamreddy, S. Burkett, and L. Schaper, J. Vac. Sci. Technol. A 23, 824 (2005).

2. R. Beica, C. Sharbono, and T. Ritzdorf, IEEE Electronic Components and Technology Conference, p.577, Kalispell, USA (2008).

3. T. Wei, J. Cai1, Q. Wang, Z. Liu, Y. Li, T. Wang, and D. Wang, IEEE International Conference on Electronic Packaging Technology \& High Density Packaging, p.483, Beijing, China (2012).

4. J. N. Broughton, M. J. Brett, S. K. Dew, and G. Este, IEEE T. Semiconduct. M. 9, 122 (1996).

5. P. F. Cheng, S. M. Rossnagel, and N. David, J. Vac. Sci. Technol. B 13, 203 (1995).

6. N. Motegi, Y. Kashimoto, K. Nagatani, S. Takahashi, T.
Kondo, Y. Mizusawa, and I. Nakayama, J. Vac. Sci. Technol. B 13, 1906 (1995).

7. T. Saito, T. Hashimoto, N. Ohashi, T. Fujiwara, and H. Yamaguchi, Mater. Trans. 43, 1599 (2002).

8. S. M. Rossnagel, C. Nichols, S. Hamaguchi, D. Ruzic, and R. Turkot, J. Vac. Sci. Technol. B 14, 1819 (1996).

9. Y. Yamamura and K. Muraoka, Nucl. Instrum. Methods B 42, 175 (1989).

10. D. G. Coronell, E. W. Egan, G. Hamilton, A. Jain, R. Venkatraman, and B. Weitzman, Thin Solid Films 333, 77 (1998).

11. T. S. Cale, T. H. Gandy, G. B. Raupp, and M. Ramaswami, Thin Solid Films 206, 54 (1991).

12. J. E. Mahan, Physical Vapor Deposition of Thin Films, pp. 222, John Wiley \& Sons, NewYork (2000).

13. I. A. Blech and H. A. Vander Plas, J. Appl. Phys. Lett. 54, 3489 (1983).

14. T. Smy, L. Tan, K. Chan, R. N. Tait, J. N. Broughton, S. K. Dew, and M. J. Brett, IEEE Electron. Device Lett. 45, 1414 (1998).

15. S. Dew, T. Smy, and M. Brett, Appl. Phys. Lett. 33, 1140 (1994).

16. A. A. Mayo, S. Hamaguchi, J. H. Joo, and S. M. Rossnagel, J. Vac. Sci. Technol. B 15, 1788 (1997).

17. N. Motegi, Y. Kashimot, K. Nagatani, S. Takahashi T. Kondo, Y. Mizusawa, and I. Nakayma, J. Vac. Sci. Technol. $B$ 13, 1906 (1995).

18. J. N. Broughton, M. J. Brett, S. K. Dew, and G. Este, IEEE Trans. Semiconduct. Manufact. 9, 122 (1996).

19. J. Zhang, X.-L. Cheng, T.-B. Wu, B.-B. Ni, R. Jiang, E.-F. Liu, Q.-Y. Huang, and H. Zhou, 2006 8th International Conference on Solid-State and Integrated Circuit Technology Proceedings, p.333, IEEE, Shanghai, China (2006).

20. N. Martin and J. Y. Rauch, Surf. Coat. Tech. 107, 172 (1998).

21. J. C. Tsao, C. Pu, Y. L. Wang, K. Chen, and K. Y. Lo, J. Phys. Chem. Solids 69, 561 (2008).

22. K. C. Park, I. R. Kim, B. S. Suh, S. M. Choi, W. S. Song, Y. J. Wee, S. G. Lee, J. H. Chung, S. R. Hah, J. H. Ah, K. T. Lee, H. K. Kang, and K. P. Suh, IEEE T. Semiconduct. M. 9, $122(2003)$.

23. H. L. Brown, S. A. Thornley, S. J. Wakeham, M. J. Thwaites, R. J. Curry, and M. A. Baker, J. Phys. D: Appl. Phys. 48, 335303 (2015).

24. Y. Yamamura and H. Tawara, Atomic Data. Nucl. Data 62 , 149 (1996). 